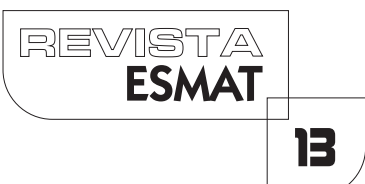

\title{
A VIDA NUA DOS DOENTES MENTAIS ENCARCERADOS NO TOCANTINS: EXTENSÃO DO ZWń E HOMO SACER NA SOCIEDADE MODERNA
}

\author{
THE NAKED LIFE OF MENTALLY RETARDED INDIVIDUALS IN THE STATE OF \\ TOCANTINS: EXTENSION OF ZWÚ AND HOMO SACER IN MODERN SOCIETY
}

Tarsis Barreto Oliveira

Doutor e mestre em Direito pela UFBA. Professor adjunto de Direito Penal da Universidade Federal do Tocantins. Professor do Mestrado em Prestação Jurisdicional e Direitos Humanos da UFT/ESMAT. Membro do Comité International des Pénalistes Francophones e da Association Internationale de Droit Pénal. Autor de obras jurídicas.

Bernardino Cosobeck da Costa

Mestre em Prestação Jurisdicional e Direitos Humanos pela Universidade Federal do Tocantins (UFT). Graduado em Direito. Professor de Prática Forense Penal da Faculdade Integrada de Ensino Superior de Colinas do Tocantins/TO. Advogado criminalista.

\section{RESUMO}

Trata-se de um estudo de caso a partir dos Autos do Processo da Ação Civil Pública n 00000 17-04.20 17.827.2721, que tramita na I ${ }^{\mathrm{a}}$ Vara Civil da Comarca de Guaraí, estado do Tocantins, Brasil, tendo como objeto os doentes mentais, desprovidos de medicação e acompanhamento psiquiátrico, em situação de encarceramento. Registrase, nesta pesquisa, uma realidade de coisificação do homem, cenário onde homens são postos à própria sorte, em que, por exemplo, verifica-se a ingestão de excrementos, ausência de leito, dentre outras condições degradantes. Assim, o sentido do presente artigo é investigar quais as estruturas que mantêm esta problemática, partindo-se de teóricos como Giorgio Agamben e Jürgen Habermas, dente outros, a fim de buscar compreender as estruturas que mantêm esta realidade.

PALAVRAS-CHAVE: Doentes Mentais; Encarceramento; Estado do Tocantins; Brasil.

\section{ABSTRACT}

This is a case study based on the records of the public civil action no. 0000017 - 
04.2017.827.2721, which is being processed in the I st Civil Court of the District of Guaraí, State of Tocantins, Brazil, with the purpose of mental patients, deprived of medication and psychiatric monitoring, in a situation of incarceration. It is recorded in this research the reality of a human degrating experience, in a scenario where men are put to their own fate, in which, for example, with ingestion of excrement, being deprived of bed, among other degrading conditions. Thus, the purpose of this article is to investigate the structures that maintain this problematic, making use of theorists such as Giorgio Agamben and Jürgen Habermas, and others, in order to seek to understand the structures that maintain this reality.

KEYWORDS: Mental Patients; Incarceration; State of Tocantins; Brazil.

\section{IINTRODUÇÃO}

Há cerca de 200 ou 150 anos (FOUCAULT, 2002, p. 19), o sistema repressivo voltado ao doente mental passou por uma ruptura, em especial a partir da adoção do sistema vicariante, na Europa, onde novos valores passaram a colocar em xeque a conveniência de se aplicar uma sanção criminal àquele que não possuía consciência do ato ilícito praticado.

A partir dessa ruptura, firmou-se o entendimento de que, em casos de ausência de compreensão do ato ilícito praticado, não poderia o doente mental sofrer aflição diante da nova sistemática jurídica. Em outros termos, se a pena agora possuía caráter teleológico para correção do homem delinquente visando à reinserção deste no meio social, para o doente mental tal finalidade se perderia com a aplicação da pena, haja vista a ausência de discernimento deste para com suas condutas. (TOURINHO FILHO, 2007, p. 238).

ordenamento jurídico deve ser coeso com a sua própria pretensão de legitimidade e validade (CANOTILHO, 2002, p. I .2 I 0). Partindo dessa ótica, o Direito Penal compreendeu, com o transcorrer dos tempos, ser desarrazoado aplicar pena para o doente mental que nem sequer tivera compreensão da violação legal praticada. Assim é que a Lei de Execução Penal brasileira, n 7.210, de 1984, em seu artigo 171 e seguintes, pôs o doente mental num espaço diferente, espaço este onde não haveria mais aplicação de pena, senão de medida de segurança e suas modalidades, seja em tratamento ambulatorial, ou, ainda, com internação em hospital de custódia ou ala psiquiátrica. Assim, passou-se da culpabilização para um instrumento com caráter curativo, preservando a saúde mental do indivíduo, sendo este o viés que o transcurso do tempo acabou postulando na ordem jurídica.

Se não se admitia mais um doente mental em cela de cadeia submetido a condições degradantes, sendo-Ihe válido tratamento adequado, a Lei n 10.216 , de 200 I, por seu turno, fazendo marco na reforma psiquiátrica, acudiu à necessidade de se reduzirem 
leitos, tornar a internação do doente mental ultima ratio, reservando tais internações quando inevitáveis, mas sempre com a premissa de haver tratamento psiquiátrico humanizado, reinsersante socialmente, e tendo como matriz o doente mental em seu direito à convivência familiar' .

Nesse entremeio, o estado do Tocantins, quando de sua criação, no artigo I 3 do Ato das Disposições Constitucionais Transitórias, não previa política pública concreta voltada para o indivíduo que estivesse em regime de medida de segurança².

Com efeito, até o ano de 2013 contam-se 23 hospitais de custódia e tratamento psiquiátrico e 3 alas de tratamento psiquiátrico no Brasil (DINIZ, 20I3, p. I4), inexistindo estabelecimento no Tocantins até o ano de $2017^{3}$.

Dessa maneira, nos Estados-Membros brasileiros, em sua quase totalidade, por inexistirem hospitais de custódia e tratamento psiquiátrico ou alas de tratamento, o doente mental submetido à medida de segurança acaba na carceragem como se estivesse cumprindo pena (BITENCOURT, 20 I2, p. 838). É justamente este o objeto dos Autos do Processo da Ação Civil Pública, onde temos como marco no Tocantins a discussão deste problema no meio jurídico por meio de um caso agora judicializado.

A base teórica que constituiu o sistema vicariante, impondo ao doente mental espaço mais humanizado, dadas suas condições especiais de saúde, na realidade social, faz-se em espaço degradante, como nos tempos anteriores ao do sistema vicariante. Assim, um doente mental infrator é posto em cela de cadeia desprovido de atenção médico-psiquiátrica, em situação degradante, como será demonstrado, com ocorrência de práticas de suicídio.

Na premissa acima, o que se buscará ao longo deste artigo é indagar quais estruturas mantêm essa realidade, procurando, no bojo dos Autos do Processo da Ação Civil Pública, integrar aquela posta nos Autos do processo em questão perante alguns teóricos.

Mais do que revelar a problemática, busca-se desvendar as estruturas que a mantêm, estudando suas variáveis, e, assim, possibilitar, a partir dessa compreensão, elucidar e, ao mesmo tempo, propor as medidas que poderiam minimizar o problema em apreço.

\footnotetext{
' Não mais se crê, realisticamente, na eficácia do confinamento como solução punitiva. A este respeito, asseveram Giacoia e Hammerschmidt (2012, p. 98): "hoy, ya no se tienen muchas esperanzas en los resultados socializadores de la prisión tradicional. Por tal razón se ha caminado en el estúdio de medidas alternativas, reservando el instrumento penal solo para nos casos de necesidad social absoluta".

${ }^{2}$ Autos do processo da ação civil pública nº 00000 I7-04.20 I7.827.272I que tramita na I ${ }^{a}$ Vara Civil da Comarca de Guaraí, estado do Tocantins, Brasil, petição inicial, evento 0 I .

${ }^{3}$ Informações contidas nos autos do processo da ação civil pública (objeto deste artigo).
} 
Em suma, numa prática de transgressão, não se investiga trazer à luz o problema em si, que já se faz evidenciado por inúmeros relatórios, fotografias, filmagens, dentre outros instrumentos probantes constantes nos Autos do processo da ação civil pública em questão, buscando-se, do contrário, perquirir o que vem perpetuando tal realidade, ou seja, quais os instrumentos científicos que podem descortinar aquilo que mantém este cenário.

Nesse sentido, partiremos de uma breve análise dos Autos do processo da ação civil pública nº 00000 17-04.20 17.827.2721, que tramita na I ${ }^{a}$ Vara Civil da Comarca de Guaraí, estado do Tocantins, focando o caso concreto que revela a coisificação do homem; em seguida, passaremos à confrontação entre Giorgio Agamben e Jürgen Habermas, no que diz respeito à extensão do homo sacer e à ação estratégica estatal, a fim de desvelar, aos moldes de Michel Foucault, o sistema de veridição.

\section{PANORAMA DOS AUTOS DO PROCESSO DA AÇÃO CIVIL PÚBLICA E O CASO DEF.A.S.S}

Em 10 de janeiro de 2017, após 8 anos de provocação ao Ministério Público Estadual e Defensoria Pública Tocantinense, a sociedade civil, solitariamente, por via de movimentos da Igreja Católica, resolveu protocolar ação civil pública, gerando, assim, os

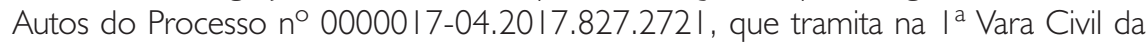
Comarca de Guaraí, estado do Tocantins ${ }^{4}$.

Os sujeitos ativos da ação retrataram uma situação já denunciada na Comissão Interamericana de Direitos Humanos, com registros antigos e atuais de casos em que se denotam graves violações de direitos elementares à pessoa, como a situação de doentes mentais desprovidos de tratamento psiquiátrico, postos em cela de cadeia, sem acesso à medicação, dentre outras situações ${ }^{5}$.

Nos Autos da referida Ação Civil Pública é consignada a situação em que diversos doentes mentais praticaram suicídio diante da situação degradante posta pela omissão estatal, e nenhum dos casos com indenização custeada pelo Estado. Há registros ${ }^{6}$, por via de documentos oficiais nestes Autos em estudo, em que o Juízo de primeira instância sentenciou pela indenização; no entanto, o Tribunal de Justiça do Estado do Tocantins entendeu, no prisma da reserva do possível, não ser cabível indenização ao doente mental preso indevidamente.

\footnotetext{
${ }^{4}$ Consulta processual no sítio do Tribunal de Justiça do estado do Tocantins, em 16/4/20 I7, às

I 9h I I min,eprocl.tjto.jus.br/eprocV2_prod_I grau/controlador.php?acao= processo_seleciona r\&acao_origem $=$ processo_consultar_nome_parte\&acao_retorno $=$ processo_consultar_nome _parte\&num_processo $=0 \overline{00} 000170 \overline{2} 20178 \overline{2} 7272 \mathrm{I} \& \mathrm{hash}=\mathrm{b} 9 \mathrm{~b} 47 \mathrm{fb} 2200 \mathrm{c} 7 \overline{\mathrm{e}} 4 \mathrm{c} 3 \mathrm{bdbF} 7 \overline{6} \mathrm{e} / \mathrm{f7b}$ 5594.

${ }^{5}$ Autos do processo ora citado, p. 6 a 12.

${ }^{6}$ Autos do processo ora citado, p. 13 a 15.
} 
Os casos concretos registrados deflagram doentes mentais postos há anos, alguns por 8 ou 9 anos, em cela de cadeia, sem acesso à medicação, ou mesmo desprovidos de leito para dormir. Remanesce registro de alguns grupos de doentes mentais que chegaram a ficar indevidamente presos em cela de cadeia, ou mesmo presídio, por 10 , ou quase 30 anos.

Postos, em regra, em celas de cadeia, alguns doentes mentais, no entanto, por apresentarem comportamento agressivo com outros presos, foram de lá retirados, porém postos em área destinada ao banho de sol, ficando, dessa maneira, às intempéries, sob sol e chuva, dormindo, mormente, no chão ${ }^{7}$. Nessas ocorrências, visualizaram-se inúmeros casos de suicídio, geralmente praticados com enforcamento ou mutilação dos punhos.

Também há registro em que doente mental, preso em flagrante delito por portar arma de fogo de brinquedo, teria sido espancado, a ponto de ter seu ombro esquerdo deslocado e costelas fraturadas, além de ter sido posto em cela de cadeia por cerca de 5 dias.

Consta dos Autos o reconhecimento do Estado-Juiz que, não obstante a documentação probante juntada aos Autos, fez alusão à instalação de verdadeiros campos de concentração no Tocantins, onde a degradação humana é restaurada como em campos nazistas ${ }^{8}$, ao que o Judiciário, em sede de tutela antecipada, condenou o Tocantins a tomar uma série de providências paliativas de urgência, sob multa de I,2.(um milhão e duzentos mil reais), sem prejuízo de reformar o valor da multa.

Para evidenciar as práticas desumanas ${ }^{9}$, citaram-se, na referida ação civil pública, inúmeros casos concretos, em especial o referente a F. A. S. S, ao que nos ateremos aqui, por se tratar de um caso que traz traços idênticos a todos os demais, além de se tratar de situação em que um doente mental no Tocantins permaneceu por mais tempo preso indevidamente em cela de cadeia.

Assim, observando o dito no parágrafo anterior, os registros em documentos oficiais que atestam toda a degradação humana de F. A. S. S constam nos Autos do Processo de Execução Penal nº 17 , de 1997, que tramitou, na $2^{a}$ Vara Criminal e Execuções Penais da Comarca de Araguaína/TO, desprovido de segredo de justiça, tendo sido digitalizado e, agora, estando disponível nos Autos do Processo Virtual n 5000407 -

\footnotetext{
${ }^{7}$ Autos do processo ora citada, p. 5 a 22.

${ }^{8}$ Autos do processo ora citado, p. 249 a 298.

${ }^{9}$ Consoante afirma Duarte (2013, p. 45): "O ingresso na prisão de um qualquer ser humano implica, não só a entrada num meio deletério e hostil, mas também, uma interrupção, uma quebra, uma perda da relação do recluso com o seu meio familiar, social e laboral".
} 
96.20 I 2.827.274 I no sítio eletrônico ${ }^{10}$ do Tribunal de Justiça do Estado do Tocantins, podendo ser objeto de consulta pela internet.

Por meio de inspeção carcerária" da Subseção da Ordem dos Advogados do Brasil da circunscrição de Colinas do Tocantins/TO, verificou-se, que F. A. S. S, analfabeto, lavrador, praticamente mudo, doente mental, fora exposto à ausência do direito à saúde, estando desprovido de medicação controlada por anos (quase 3 décadas), além de não estar recebendo tratamento especializado da saúde.

$\mathrm{Na}$ inspeção acima referida, ficou demonstrado que F. encontrava-se em cela improvisada, na Cadeia Pública de Colinas do Tocantins/TO, com mais I 4 presos. Ele estaria dormindo no chão e não teria asseio com sua higiene, em razão de não haver leito ou mesmo material de higiene propiciado pelo estado do Tocantins.

O doente mental F. A. S. S reflete apenas um dentre outros inúmeros casos registrados nos Autos do Processo da Ação Civil Pública em comento, porém, em especial, o caso de F. registra uma prisão de quase 3 décadas, em regime prisional fechado, com registros de ingestão de suas próprias fezes e urina, quando a lei the deveria garantir tratamento diverso, humanizado ${ }^{12}$.

Nesse cenário, em 12 de junho de 1996, tendo informação de que F. estaria com perturbação mental, o juiz da Execução Penal de Gurupi, estado do Tocantins, decidiu' ${ }^{13}$ por indeferir a progressão de regime prisional, determinando que psicólogos avaliassem F., pois este, em liberdade, poderia pôr em risco a coletividade.

Apesar da inexistência de laudo de especialistas em equipe interprofissional, ou ao menos de um psiquiatra que atestasse a debilidade mental de F., em 30 de outubro de 1996, por via do Ofício n 405, de 1996, o delegado de Polícia Civil de Miracema, estado do Tocantins, narrou ao Juízo da Execução Penal daquela Comarca que F. era um alienado mental, amparando-se nas declarações prestadas por outro preso ${ }^{14}$.

No termo de declaração ${ }^{15}$ de preso companheiro de cadeia de F. foi relatado que este estaria conversando com pessoas invisíveis, além de estar se alimentando de suas próprias fezes, andando despido em cela de cadeia, rasgando seu próprio colchão, tendo episódios de insônia, mormente entre 3 e 4 dias seguidos.

\footnotetext{
${ }^{10}$ Consultado no sítio eletrônico do Tribunal de Justiça do estado do Tocantins, disponível em https://eprocl.tjto.jus.br/eprocV2_prod_I grau/controlador.php?acao=processo_selecionar\&a cao_origem $=$ processo_consultar_nome_parte\&acao_retorno $=$ processo_consultar nome_parte\&num_processo $=50004079620128272741$ \&hash $=21$ 9bc9c43f6996 $16857 \mathrm{~b} 9 \mathrm{e} \overline{5}$ 0830b667a. Consulta realizada em 15 de agosto de 2008.

"Inspeção Carcerária n 00 I , de 20 I 4, da OAB/TO da Subseção de Colinas do Tocantins/TO.

${ }^{12}$ Autos do processo digitalizado sob o n 5000407-96.20 I2.827.274I , p. 16.

${ }^{13}$ Autos do processo, p. 82/83.

${ }^{14}$ Autos do processo, p. I | 8// 20.

${ }^{15}$ Autos do processo, p. $120 / 180$.
} 
Em Araguaína/TO, já no ano de 1996, pelo Ofício n 127, de 1996, o diretor da Unidade Prisional registrou que F. vinha apresentando sintomas de desequilíbrio mental, como, por exemplo, comer suas próprias fezes, beber urina, além de andar despido pela cela de cadeia, pondo em risco a vida dele e a de outros presos. O diretor, nesse sentido, requereu ao Juízo da Execução da Pena de Araguaína/TO para que F. fosse retirado do ambiente carcerário, nos termos da lei, e assim, devendo ser recambiado para a Clínica de Repouso São Francisco ${ }^{16}$.

Desde o início, percebe-se que F. deveria ter sido alocado, ainda que provisoriamente, em ambiente médico para avaliações, coisa que ainda restaria muitos anos para ser feito. Essa situação que deflagra morosidade na tomada de iniciativas para diagnosticar o suposto doente mental é reproduzida reiteradamente em casos análogos, como bem se percebe na petição inicial dos Autos da Ação Civil Pública em destaque neste artigo, onde se registram diversos processos judiciais.

Em avaliação psiquiátrica, naquele mesmo ano, obteve-se o diagnóstico, no qual F. seria portador de uma "(...) personalidade psicótica e, portanto, com periculosidade manifesta, não podendo ser internado em hospital psiquiátrico comum (...)" ${ }^{m / 7}$, e aconselhando que o Juízo da Execução Penal de Araguaína/TO encaminhasse o doente mental para o manicômio judicial.

Já passados alguns anos, em 16 de maio de 1997, foi confeccionado outro laudo psiquiátrico, reafirmando que F. teria, de fato, personalidade psicótica, sendo uma doença mental congênita, e mais, frisando a necessidade de ser internado em manicômio judicial, fazendo uso de medicamentos.

No mesmo laudo psiquiátrico, algo já público, fora frisado o fato de que no estado do Tocantins inexiste estabelecimento adequado para tratamento de F., assim como nos estados de Goiás, Maranhão e outros tantos da Federação brasileira ${ }^{18}$.

A partir de então, a coisificação de F. transcende a sua própria figura, reproduzindo uma prática reiterada em que doentes mentais permanecem em ambiente carcerário em detrimento da legislação e tratados internacionais dos quais o Brasil é signatário.

Parecer do Ministério Público, datado de 24 de novembro de 2005, revelou que o caso em estudo vem a retratar uma "(...) situação desumana em que se encontra o condenado, sem qualquer tipo de assistência psiquiátrica (...)"..$^{9}$ O promotor de justiça ainda grafou que $F$. deveria ser reavaliado por psiquiatra, em razão de a última avaliação ter sido feita há mais de 8 anos.

\footnotetext{
${ }^{16}$ Autos do processo, p. 134

${ }^{17}$ Autos do processo, p. 145.

${ }^{18}$ Autos do processo, p. 169-170.

${ }^{19}$ Autos do processo, p. 223.
} 
No lastro de quase uma década, F. não obteve do estado do Tocantins reavaliação psiquiátrica para saber qual seu estado de saúde mental, quais medicamentos deveriam ser ministrados, quais os possíveis tratamentos e cuidados deveriam ser despendidos para ele.

Tal reavaliação nunca fora feita, em razão de não ter havido psiquiatra custeado pelo Estado, e o que se dispôs a realizar novo exame cobrou para tanto $\mathrm{R} \$ 300,00$ (trezentos reais) para fazer dita reavaliação ${ }^{20}$. Tendo o Estado se recusado tacitamente a adimplir a consulta médica, F. permanece sem a referida reavaliação psiquiátrica.

Diagnosticado como esquizofreniforme e personalidade psicótica ${ }^{21}$. F., com tentativas de suicídio, permaneceu preso, desprovido de tratamento de saúde mental ${ }^{22}$, com seus braços mutilados, sem corte de cabelo ou mesmo barba, apenas apresentando um sorriso constante e olhos vítreos em pontos perdidos da cela de cadeia, ingerindo suas fezes e urina e dormindo no chão.

No passar dos anos, diversos magistrados solicitaram vaga para internação de F. em inúmeros estados da Federação (Sergipe, Rio de Janeiro, Rio Grande do Sul, Minas Gerais, Rio Grande do Norte, Paraná, São Paulo, Bahia, Alagoas, Ceará, Pernambuco, Santa Catarina, dentre outros), sempre sem sucesso ${ }^{23}$, em razão de inexistir ambiente hospitalar para acolhê-lo, ou, noutras vezes, mesmo existindo Hospital de Custódia, não haver vaga para realizar internação.

Dados mais de 17 anos, já em 17 de outubro de 2007, por via do Ofício n³36, de 2007, o Juízo da causa manifestou-se à Corregedoria do Judiciário do Estado do Tocantins de que o Centro de Atenção Psicossocial (CAPS), de Araguaína/TO, ao menos mediaria F. no ambiente carcerário. Nenhum processo da Corregedoria foi instaurado, tampouco medida para sanear efetivamente a questão de F.

Consta dos Autos do processo em análise que o primeiro agendamento para consulta no Centro de Atenção Psicossocial (CAPS), de Araguaína/TO, deu-se somente em 3 de dezembro de 2008, conforme pontua o Ofício n 397, de 2008, com a palavra expressa em seu cabeçalho RÉU PRESO ${ }^{24}$.

Apesar da intervenção do Centro de Atenção Psicossocial no caso aqui exposto, verificou-se que a consulta psiquiátrica para reavaliação nunca se realizou efetivamente ${ }^{25}$, demonstrando os contornos de um Estado silente para com a pessoa do doente mental.

\footnotetext{
${ }^{20}$ Autos do processo, p. 228.

${ }^{21}$ Autos do processo, p. $310-312$.

${ }^{22}$ Autos do processo, p. 339-340.

${ }^{23}$ Autos do processo, p. 392-410 e 477.

${ }^{24}$ Autos do processo, p. 466.

${ }^{25}$ Autos do processo, p. 47I.
} 
O caso de F., como os de outros citados nos Autos do Processo da Ação Civil Pública em comento, viu-se abandonado pelo estado do Tocantins ${ }^{26}$. Até 12 de novembro de 20 I 4, F. A. S. S. aguardou em cela de cadeia, por quase 25 anos sem tratamento médico, quando então foi expedido alvará de soltura ${ }^{27}$, conquistando, assim, a liberdade, para cumprir medida de segurança de internação.

Por quase 3 décadas, aguardou o doente mental um tratamento médico, tendo obtido como resposta apenas sua segregação ilegal que ainda lhe introjetaria o sistema carcerário para sempre, como veremos a seguir.

Em Araguatins/TO, F. se encontra numa Casa Terapêutica de Longa Permanência; porém, apesar de estar em liberdade e ter à sua disposição um leito para dormir, ele não dorme no leito, permanece no chão ${ }^{28 .}$ Os quase 25 anos de prisão introjetaram em $\mathrm{F}$. o direto de não ter direito, não lhe sendo assimilável, após tantas décadas, o direito de dormir numa cama, ou leito.

No mesmo relatório que demonstra o dito acima, é consignado que F. não consegue assimilar seu direito à liberdade, por exemplo, não consegue ligar ou desligar o interruptor de luz assim como numa cadeia, ou presídio, já que os presos não detêm o direito de acender ou apagar uma lâmpada ${ }^{29}$.

O estado do Tocantins, por seu turno, em 28 de março de 2017, sob a alegação da reserva do possível e de que não há orçamento para a consecução de Hospital de Custódia, ou Alas Psiquiátricas, voltadas para esses doentes mentais, fez contestação à ação civil pública, que no momento se encontra conclusa para deliberação judicial desde então.

Casos outros poderiam ter sido retratados neste artigo; no entanto, todos os casos consignados na ação civil pública em estudo retratam a mesma maneira manifesta de práticas, quais sejam: a) o doente mental que pratica um ilícito permanece, em regra, em cela de cadeia ou pátio da carceragem; b) no ambiente carcerário, o doente mental, dificilmente, ou quando em regra, não obtém acompanhamento médico adequado à sua saúde mental; c) há um discurso estratégico do Estado sob a alegação de limitações orçamentárias, o que impediria de serem tomadas providências em favor do doente mental; d) verifica-se, no caso concreto, uma aparente peça teatral, na qual os signos, ou símbolos, retratam a aplicabilidade da lei, não possuindo efetividade sob as amarras do Estado; e) há um discurso que prefere e legitima a coisificação do homem em favor da coletividade, diante do problema orçamentário e sob uma premissa de segurança pública; f) quando indenizações são pleiteadas em razão desse problema, em regra, o

\footnotetext{
${ }^{26}$ Autos do processo, p. 488.

${ }^{27}$ Autos do processo de execução penal, evento | 48 e 156.

${ }^{28}$ Autos do processo de execução penal, evento 158.

${ }^{29}$ Autos do processo em estudo, p. 556 e 558.
} 
Judiciário tocantinense tem concedido valores para fins de reparações materiais e morais; no entanto, no espaço do Tribunal de Justiça Estadual, tais decisões, via de regra, são reformadas sob a alegação da reserva do possível, ou seja, tendo como cerne questões de limitações financeiras.

De toda maneira, patente também ${ }^{30}$, uma alienação social percebida no que se refere ao conceito e alcance de Direitos Humanos, enquanto, por equívoco, volta-se à ideia errônea de que Direitos Humanos compreendem um conjunto de direitos que servem para tutelar criminosos; doutro modo, esta questão ora apresentada neste artigo, é em regra de desconhecimento da coletividade, o que denota uma situação de invisibilidade social.

\section{DAIMBRICAÇÃO E DICOTOMIA TEÓRICO-PRÁTICA}

A partir do panorama acima, percebeu-se a existência de uma demanda judicializada, na qual se atenta à necessidade de garantia efetiva ao cumprimento da legislação, em que doentes mentais que tenham cometido crimes possam cumprir medida de segurança, e não pena ${ }^{3 !}$, de tal maneira que o Estado estará sendo coerente com o fundamento a que se propõe, ou seja, tutelar os direitos fundamentais do homem e, em especial, dos grupos sociais mais pauperizados.

Por meio da sistemática ora referida, com fundamento constituciona ${ }^{32}$, sob o prisma do princípio da dignidade da pessoa humana, e no contexto do presente artigo, o doente mental que tenha praticado crime terá direito ao atendimento especializado de saúde segundo a orientação da medicina psiquiátrica, com a presença de equipe multiprofissional a fim de possibilitar o tratamento adequado que venha a cessar, ou minimizar, a periculosidade do doente mental, e, assim, viabilizar sua reinserção no meio social, comunitário e familiar. (SILVA, 200 I , p. 108).

Em casos de alta periculosidade do doente mental, a modalidade de medida de segurança de internação se faz na privação de liberdade a ser cumprida em hospital de custódia e tratamento psiquiátrico ou em estabelecimento adequado com características hospitalares, como bem dispõe o inciso I do artigo 96 do Código Penal Brasileiro, imposição legal realçada no artigo 101 da Lei n 7.2 1 0, de 1984.

\footnotetext{
${ }^{30}$ Autos do processo em estudo, p. 556 e 558.

${ }^{31}$ Consulta processual junto ao sítio do Tribunal de Justiça do estado do Tocantins, em 16.04.20 I7, ás $19 \mathrm{~h}$ I I min,eprocl.tjto.jus.br/eprocV2_prod_I grau/controlador.php? acao=processo_ selecionar\&acao_origem $=$ processo_consultar_nome_parte\&acao_retorno $=$ processo_ consultar nome parte\&num_processo $=0000017042017827272$ I \&hash $=b 9 b 47 f b 2200 c 7 e \overline{4}$ c3bdb776elf7b5594.

32"Art. I $^{\circ}$. A República Federativa do Brasil, formada pela união indissolúvel dos Estados e Municípios e do Distrito Federal, constitui-se em Estado Democrático de Direito e tem como fundamentos: (...) III - a dignidade da pessoa humana;" Constituição Federal, de 1988.
} 
Nos Tribunais Estaduais e nos Superiores do Brasil, essa excepcional internação humanizada, com direito a tratamento e medicação adequada, aduz que tal medida de segurança não poderá ser cumprida jamais em cadeia pública ou presídio, senão em estabelecimento hospitalar ou com características hospitalares. (GOMES, 2007, p. 900)

É isso que o artigo 99 do Código Penal conclama: "O internado será recolhido a estabelecimento dotado de características hospitalares e será submetido a tratamento." Nesse sentido, é da doutrina jurídica (CAPEZ, 2007, p. 434), e até mesmo do entendimento pacífico do Supremo Tribunal Federal que

O local da internação: internado será recolhido a estabelecimento dotado de características hospitalares (art. 99 do CP). Na falta de vaga, a internação pode dar-se em hospital comum ou particular, mas nunca em cadeia pública (...). Desta forma, constitui constrangimento ilegal a manutenção de réu destinatário da medida de segurança em estabelecimento inadequado por inexistência de vaga em hospital. (RJTJSP, 91/388; Damásio E. de Jesus, Comentários, cit., v. 2, p. 230; JTACrimSP, 92 I 32; RT, 608/325; HC 138.478, da 8ª Câm. Do TACrimSP; HC 64.494-5-SP, 2a T., Rel. Min. Aldir Passarinho, j. 25.11.1986, unânime, DJU, 27.02.1987, p. 2953).

Porém, apesar de a Legislação Brasileira, a Doutrina Jurídica e os Tribunais de Justiça compartilharem do mesmo entendimento, o que se questiona é: Qual a razão para haver um abismo entre o disposto na ciência jurídica e as práticas do Estado-Executivo, em que este, de maneira reiterada, vem suspendendo e restringindo direitos humanos? Com efeito, constatam-se inúmeros casos concretos em que o doente mental, sob a tutela do Estado, vem sofrendo um processo de coisificação ou desumanização ${ }^{33}$.

Evidencia-se a existência (ou coexistência) de um Estado Totalitário (ou Estado de Exceção) em pleno Estado Democrático, (AGAMBEN, 2002, p. 24), porque direitos fundamentais vêm sendo reiteradamente suspendidos pelo próprio Estado. Em que pese à alegação estatal de que faltam recursos financeiros para dar vasão ao fundamental direito à dignidade e saúde em favor do doente mental, esta não se justifica, tendo em vista, a título de exemplo, o peso orçamentário que representam as publicações, propagandas, dentre outros gastos de ordem secundária, viabilizados comumente pelo Estado.

${ }^{33} \mathrm{O}$ Brasil possui um longo histórico de violações aos direitos humanos no âmbito prisional. Nesse mister, a obra Holocausto Brasileiro, de Daniela Arbex, revela inúmeras violações aos direitos dos indivíduos submetidos a medidas de segurança no maior hospício do Brasil, conhecido como Colônia, na cidade mineira de Barbacena, em Minas Gerais, palco da morte de mais de 60 mil internos, naquele que pode ser considerado um imenso genocídio brasileiro. 
Referimo-nos, pois, a um Estado de Exceção existente no Estado brasileiro, no qual há a suspensão de direitos fundamentais em razão de axiomas ou preceitos que colocam determinados grupos sociais, marginalizados, em um meio hostil, sendo-lhes privados direitos básicos, como alimentação, saúde, educação, e inúmeros outros.

Como já demonstrado no item anterior, é patente que a medida de segurança de internação não pode ser cumprida no sistema carcerário por razões legais e, mais que isso, por razões humanitárias sedimentadas nas teorias modernas. (GOMES, 2007, p. 900). No entanto, é isso que vem ocorrendo, revelando-se uma flagrante dicotomia entre teoria e prática.

Para investigarmos o que mantém tais estruturas repressivas, em que há um discurso legal não correspondido às práticas estatais, faz-se necessário remontar à figura do Z $\omega \dot{\eta}$ e Bío s enquanto expressões da cultura grega (AGAMBEN, 2002, p. 28), em que ambas

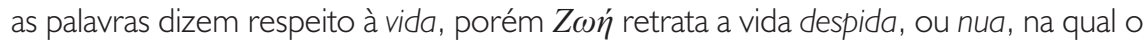
homem não teria assistência estatal em favor de direitos fundamentais, tratando-se da vida posta à natureza selvagem; e Bíos diz respeito a uma vida qualificada, com a garantia de direitos fundamentais, representando a figura do cidadão em sentido amplo.

Nesse cenário, haveria pessoas postas à $Z \omega \dot{\eta}$, uma vida despida de direitos fundamentais, na qual o Estado não se importaria, não teria ânimo real para the proporcionar direitos fundamentais. Trata-se de grupos sociais dotados de invisibilidade, com uma vida despida de direitos básicos, invisíveis porque, por meio de um discurso estratégico, o Estado, apropriando-se das técnicas e áreas do conhecimento, manipula as massas sociais a ponto de tais grupos sociais hostilizados se tornarem despercebidos, alheios à própria sorte diante da macroestrutura estatal.

Ainda assim, para além da $Z \omega \dot{\eta}$, de maneira mais refinada, encontra-se o instituto do Homo Sacer (literalmente, homem sagrado) do Direito Romano (AGAMBEN, 2002, p. 28), em que uma pessoa era excluída de todos os direitos básicos, porquanto a sua vida era considerada santa em sentido negativo. O Império Romano, assim, para determinadas pessoas ou grupos sociais, poderia declarar pelo Homo Sacer, deixando à sorte dos deuses a vida de determinada pessoa, desprovendo-a de direitos e entregue à própria sorte.

Pessoas sujeitas ao julgamento do Estado, ou Império, desnecessárias para os meios de produção, por vezes rotuladas negativamente por um etiquetamento social, poderiam ser declaradas, de maneira solene, como Homo Sacer, e assim teriam a declaração de uma vida despida ou nua de direitos fundamentais.

Ao que parece, o instituto do Homo Sacer aparenta remontar o mesmo ideal do Z $\omega \dot{\eta}$, ainda permanecendo nas sociedades contemporâneas, mesmo que com outros contornos ou signos, como num segmento helicoidal da história, tornando a se repetir ainda que em contornos e graus diversos, no entanto, preservando a essência das premissas marginalizantes diante de determinados grupos sociais.

Se o escravo torna-se servo e, por seu turno, este se transfigura em trabalhador sem mobilidade social real, tudo acaba estampado por um discurso estratégico estatal para 
manutenção dos grupos sociais. Segundo Huxley, nesse contexto de Estado de Exceção, percebe-se uma ditadura com aparência de democracia que a muitos seduz:

A ditadura perfeita terá aparência de democracia: uma prisão sem muros na qual os prisioneiros não sonharão sequer com a fuga. Um sistema de escravidão onde, graças ao consumo e ao divertimento, os escravos terão amor à escravidão do trabalho. (Huxley, 20।4, p. 122).

Evidenciados esses signos com aparentes contornos diversos, mas essência similar, ainda nessa imbricação, cabe inquirir o que mantém a extensão da $Z \omega \eta$, por este Estado de Exceção com forma de democracia, a determinados grupos sociais hostilizados.

Com esse questionamento, poderíamos compreender, por meio de Habermas (1987), que é possível haver dissociação entre a legalidade e a legitimidade em decorrência de uma quebra de mandato, quando o representante não representa mais o seu representando. Mera legitimidade formal, faltando-lhe a legitimidade material (ou legitimidade de fato) de nossos representantes públicos.

Nessa lógica da premissa em pauta, poder-se-ia falar em esvaziamento de cargo/função ou perda de legitimidade funcional-material, quando um parlamentar ou chefe de governo, ao exercerem suas funções, desvirtuam-se do disposto em lei; esta seria, pois, meramente uma linguagem estratégica para a manutenção de um senso, falso, de paz social existente apenas para a manutenção do estado das coisas como estão.

Nesse sentido, legalidade e legitimidade podem se contrapor uma à outra, podendo haver ilegitimidade material quando instituições, governos ou parlamentos buscam, por meio das leis, desvirtuar a necessária busca de interesses universalizáveis (comuns à sociedade) pela busca, em seu lugar de meros interesses particulares, por vezes escusos. Nesse contexto, a própria pena constituir-se-ia um mecanismo de exclusão e de manutenção do status quo de dominação e segregação social, de tal sorte que "la pena representa el mayor instrumento del poder estatal para alcanzar sus fines" (SOUTO, 2006, p. 64).

Traçando casos concretos e obtendo a concessão de tutela antecipada nos Autos da Ação Civil Pública, objeto da pesquisa deste artigo, abre-se um campo teórico-prático para desvelar a tipologia habermasiana de ação, em especial destacando-se a ação estratégica empreendida por grupos de poder, evidenciada na confirmação do papel de exclusão das classes menos favorecidas da fruição de direitos fundamentais.

Contrapondo-se a essa ação estratégica, propõe-se a ação comunicativa, tendo como pretensão de validade a busca do entendimento entre os sujeitos, com vista, na construção comunicativa de um acordo racional, à consagração de interesses comuns aos participantes de um discurso, gerador de consenso válido entre os sujeitos.

Sendo um dos pressupostos da ação comunicativa, consoante erigido por Habermas, a preservação de uma situação de fala ideal, compreendida como a 
igualitária manifestação de atos de fala pelos sujeitos sociais, note-se que esta não ficaria inviabilizada na perspectiva do discurso relativo aos doentes mentais, porque sujeitos sociais e segmentos da sociedade poderiam/podem reivindicar argumentos que representem a salvaguarda dos interesses desses indivíduos. Ademais, embora os agentes do processo sejam interdependentes, fato é que diversos fatores sociopsicológicos (e às vezes até mesmo de ordem política ou classista, ou mesmo de ordem de debilidade mental) fazem com que não haja planificação na fala, elemento intencional da boa-fé, em que todos os interlocutores se comprometessem em compenetrar o argumento um do outro a fim de equacionar as questões postas e chegar a uma resolução.

Concretamente, a possibilidade da audiência de conciliação no caso dos Autos do Processo da Ação Civil Pública, ou, ainda, a consecução de audiência pública, pode resultar na efetividade real da ação comunicativa traçada por Habermas, na qual

\begin{abstract}
Dois ou mais sujeitos capazes de linguagem e de ação buscam o entendimento, coordenando de comum acordo seus planos de ação. Esta ação envolve o conceito central de interpretação, referindo-se à negociação de definições da situação susceptíveis de consenso, desempenhando a linguagem um papel fundamental. (OLIVEIRA, 20 I 2, p. 32).
\end{abstract}

Ao invés de judicializar questões sociais, é possível, por meio da ação comunicativa, racionalizar previamente as questões e seus fatores para, então, chegar a resoluções concretas. Mas mesmo em juízo, a ação comunicativa mostra-se favorável e viável, quando as partes do processo buscam racionalizar os argumentos opostos para chegar a um consenso válido entre os participantes.

No plano da ausência de fruição de direitos por parte dos doentes mentais, é de se notar que as causas pelas quais uma dicotomia entre norma e realidade se evidencia envolvem uma relação multifatorial, e disso se faz necessária a análise de diversas variáveis (HOFLING, 200 I , p. I0), entre as quais a mais importante diz respeito ao fator cultural, no qual se analisa o grau de aceitação ou rejeição popular de determinada política pública ou norma.

A análise do fator cultural permite analisar crenças, valores e ideias no grupo geral, ou em grupos mais fragmentados, fazendo perceber as diversas dimensões do processo de formulação de políticas públicas ou normas, disso se detectando as coalizões de defesa ou antíteses para a prática de realização de leis, ações e programas nas diversas políticas públicas. (SOUZA, 2006, p. 20-45). Com isso, podemos compreender por qual razão determinada política pública é mais implementada do que outra política - ou tem maior eficácia do que outra -, o que igualmente se denota no contexto de grupos especialmente marginalizados, a exemplo dos doentes mentais encarcerados. 


\section{CONSIDERAÇÕES FINAIS}

Os doentes mentais, postos em cela de cadeia, representam minoria social vitimizada pelo estado do Tocantins, sem acesso a tratamento psiquiátrico. Apesar de a legislação pátria e os tratados internacionais assegurarem-lhes direitos, há flagrante dicotomia entre a teoria e a prática no que preveem tais dispositivos.

Na perspectiva brasileira, podemos inferir que o grupo social, ou grupo de pessoas, que não se mobiliza politicamente, ou não tem espaço de reivindicação na democracia da maneira que seja não teria amparo concreto na formulação das leis, ou, quando o tivesse, não teria espaço para a efetividade dos direitos que lhe são devidos.

Nesse mesmo viés, no sistema capitalista aquele que não consome, ou não está inserido no processo mercadológico, não interessa ao sistema e, por conseguinte, isso afetará na formulação das normas e, às vezes, mesmo quando houver normas, resultará na ausência de efetividade delas, visto estarem apartadas do sistema de consumo em potencial, próprio da sociedade moderna capitalista (MARICATO, 2009).

No sentido de democracia, legalidade e legitimidade, podemos concluir que a ineficácia na aplicação da medida de segurança para doentes mentais, por parte do Estado, pode estar relacionada à fragmentação deste grupo social quanto à possibilidade de reivindicação de seus direitos, e à ausência de interesse social em sua guarida por outros sujeitos no campo político.

$\mathrm{Na}$ perspectiva dos grupos marginalizados, dos quais se encontram os doentes mentais, é fato que a ausência de autodeterminação psíquica, aliada à linha de miséria em que se encontram as suas famílias, somadas ao baixíssimo grau de escolaridade, implicam a exclusão destes do campo da representatividade estatal, com consequente ausência de fruição dos seus direitos fundamentais, com prejuízos incalculáveis à qualidade de vida e à dignidade desses sujeitos.

Assim, no bojo da ação civil pública em comento, abre-se oportunidade para racionalizar a problemática, a fim de minimizar os danos causados aos doentes mentais encarcerados, conferindo-lhes possibilidades mais concretas de fruição de direitos fundamentais assegurados na Constituição.

\section{REFERÊNCIAS}

AGAMBEN, Giorgio. Homo sacer: o poder soberano e a vida nua. Trad: Henrique Burigo. Belo Horizonte: Editora da UFMG, 2002.

BITENCOURT, Cezar Roberto. Tratado de direito penal: parte geral I. 17 ed. rev. e ampliada. São Paulo: Saraiva, 2012.

CANOTILHO, José Joaquim Gomes. Direito constitucional e teoria da constituição. 6 ed. Coimbra: Almedina, 2002. 
CAPEZ, Fernando. Curso de direito penal: parte geral. vol. I, I I ed. São Paulo: Saraiva, 2007.

DINIZ, Débora. A custódia e o tratamento psiquiátrico no Brasil: censo 2011 . Brasília: UNB, 2013.

GOMES, Luiz Flávio. Direito penal: parte geral. vol. 2. São Paulo: Editora Revista dos Tribunais, 2007.

HABERMAS, Jürgen. A Ética da Discussão e a Questão da Verdade. Trad. Marcelo Brandão Cipolla. São Paulo: Martins Fontes, 2004.

HABERMAS, Jürgen. Teoría de la acción comunicativa. Madrid: Taurus, 1987.

HOFLING, Eloisa de Mattos. Estado e políticas (públicas) sociais. Cad. CEDES. 200 I , vol.2I, n.55, p. 30-4l. Disponível em: <http://www.scielo.br/pdf/ccedes/v2 In55 /5539.pdf>. Acesso em: 10 jun. 2017.

HUXLEY, Aldous. Admirável Mundo Novo. Tradução: Lino Vallandro. São Paulo: $\bigcirc$ Globo, 2014, p. 122.

Inspeção Carcerária n 001/2014 da OAB/TO da Subseção de Colinas do Tocantins/TO.

OLIVEIRA, Tarsis Barreto. Pena e Racionalidade. Rio de Janeiro: Lumen Juris, 2012.

RJTJSP, 91/388; Damásio E. de Jesus, Comentários, cit., v. 2, p. 230; JTACrimSP, 92 I 32 ;

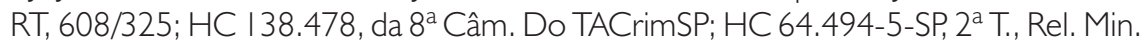
Aldir Passarinho, j. 25. I I. 1986, unânime, DJU, 27.02.1987.

SILVA, Haroldo Caetano da. Manual da execução penal. Campinas: Bookeller, 2001 .

SOUZA, Celina. Políticas públicas: uma revisão da literatura. Sociologias, Porto Alegre, n. 16, p. $20-45$, dezembro de 2006. Disponível em: <http://www.scielo.br/pdf/soc/n 16/a03n16>. Acesso em: I0 jun. 2017.

TOURINHO FILHO, Fernando da Costa. Prática de processo penal. 28 ed. São Paulo: Saraiva, 2007.

TRIBUNAL DE JUSTIÇA DO TOCANTINS. Ação Civil Pública nº 0000017 - 
04.2017.827.2721, I a Vara Cívil da Comarca de Guaraí/TO. Disponível em: https://eprocl .tjto.jus.br/eprocV2_prod_I grau/controlador.php?acao=processo_sele cionar\&acao_origem $=$ processo_consultar_nome_parte\&acao_retorno $=$ processo_c onsultar_nome_parte\&num_processo $=0000017042017827272$ I \&hash $=b 9 b 47 f b 2$ 200c7e4c3bdbf76e If7b5594.

TRIBUNAL DE JUSTIÇA DO TOCANTINS. Execução Penal n 5000407 96.2012.827.2741, Vara de Execuções Penais de Juízo da la Vara Criminal de Araguatins/TO. Disponível em: https://eprocl.tjto.jus.br/eprocV2 prod_I grau/controlador.php?acao=processo_selecionar\&acao_origem $=$ processo_c onsultar_nome_parte\&acao_retorno=processo_consultar_nome_parte\&num_proc

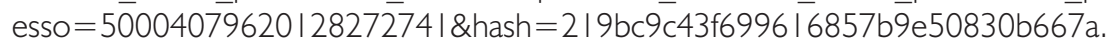


